\title{
A first classification scheme of flow-bed interaction for clay- laden density currents and soft substrates
}

\author{
Verhagen Iris Thérèse Elise ${ }^{1,}{ }^{*}$, Baas Jaco Hugo ${ }^{1}$, Silva Jacinto Ricardo ${ }^{2}$, McCaffrey William Dale ${ }^{3}$, \\ Davies Alan Geoffrey ${ }^{1}$
}

${ }^{1}$ Bangor Univ, Sch Ocean Sci, Menai Bridge LL59 5AB, Ilse Of Anglese, Wales.

2 IFREMER, Ctr Brest, Marine Geosci Unity, Plouzane, France.

${ }^{3}$ Univ Leeds, Sch Earth \& Environm, Leeds LS2 9JT, W Yorkshire, England.

Corresponding author : Iris Thérèse Elise Verhagen email address : ospa03@bangor.ac.uk

\begin{abstract}
:
Many aquatic environments exhibit soft, muddy substrates, but this important property has largely been ignored in process-based models of Earth-surface flow. Novel laboratory experiments were carried out to shed light on the feedback processes that occur when particulate density currents (turbidity currents) move over a soft mud substrate. These experiments revealed multiple types of flow-bed interaction and large variations in bed deformation and bed erosion, which are interpreted to be related to the interplay between the shear forces of the current and the stabilising forces in the bed. Changes in this force balance were simulated by varying the clay concentrations in the flow and in the bed. Five different interaction types are described, and dimensional and non-dimensional phase diagrams for flow-bed interaction are presented.
\end{abstract}

Keywords : Turbidity currents, Cohesive substrates, Flow-substrate interaction, Flume experiments, Phase diagram 


\section{Introduction}

Turbidity currents are particulate gravity currents that move owing to a density difference between the particle-laden flow and the ambient fluid. They are considered the primary mech-anism for sediment transport in the deep-marine environ-ment, but due to their infrequent and destructive behaviour

I.T.E. Verhagen $(\bowtie) \cdot$ J.H. Baas · A.G. Davies

School of Ocean Sciences, Bangor University, Menai Bridge, Ilse of Anglesey, LL59 5AB, United Kingdom

E-mail: ospa03@bangor.ac.uk

R.S. Jacinto

Ifremer, centre de Brest, Marine Geosciences Unity, BP 70, Plouzané, France

W.D. McCaffrey

School of Earth and Environment, University of Leeds, Leeds, LS2 9JT only few studies have observed turbidity currents in the natural environment (Khripounoff et al, 2003; Xu et al, 2004; Hsu et al, 2008).

Instead, experimental studies have been undertaken to investigate turbidity currents under controlled laboratory conditions (e.g. reviews by Middleton, 1993; Kneller and Buckee, 2000). Recent experimental studies have investigated the effects of clay on flow properties (Coussot, 1997; Marr et al, 2001; Baas and Best, 2002; Felix and Peakall, 2006; Baas and Best, 2008; Baas et al, 2009; Chowdhury and Testik, 2011), the interaction of flows with a non-cohesive substrate (Butler and Tavarnelli, 2006; Eggenhuisen et al, 2010; Eggenhuisen and McCaffrey, 2011) and fluid mud processes and erodibility of cohesive beds (Mehta, 1991; Kineke et al, 1996; Houwing and Van Rijn, 1994; Houwing and van Rijn, 1998; Kothyari and Jain, 2010; Baas et al, 2011; Dickhudt et al, 2011; Jacobs et al, 2011; Baas et al, 2013). However, the interaction between clay-laden turbidity currents and soft, deformable or erodible beds has not yet been explored.

Soft, muddy sediments with concentrations between several to hundreds of $\mathrm{kg} \mathrm{m}^{-3}$ are referred to as fluid mud deposits (see Nichols, 1984; Odd and Cooper, 1989; Kineke et al, 1996; Whitehouse et al, 2000; Winterwerp and van Kesteren, 2004; McAnally et al, 2007a). Winterwerp and van Kesteren (2004) defined fluid mud as a cohesive sediment suspension with a concentration at or beyond the gelling point, in the order of several 10 to $100 \mathrm{~kg} \mathrm{~m}^{-3}$. This concentration range is used in the present study as the interval in which a fluid mud can develop ('fluid mud domain').

Fluid muds in the natural environment are formed by rapid sedimentation or liquefaction of mud deposits (Whitehouse et al, 2000; Winterwerp and van Kesteren, 2004) and they can form in any water body with sufficient fine-sediment supply and periods of low intensity flow (McAnally et al, 2007a). Examples of natural occurrences of fluid mud include harbour basins and navigational channels, like the Sa- 


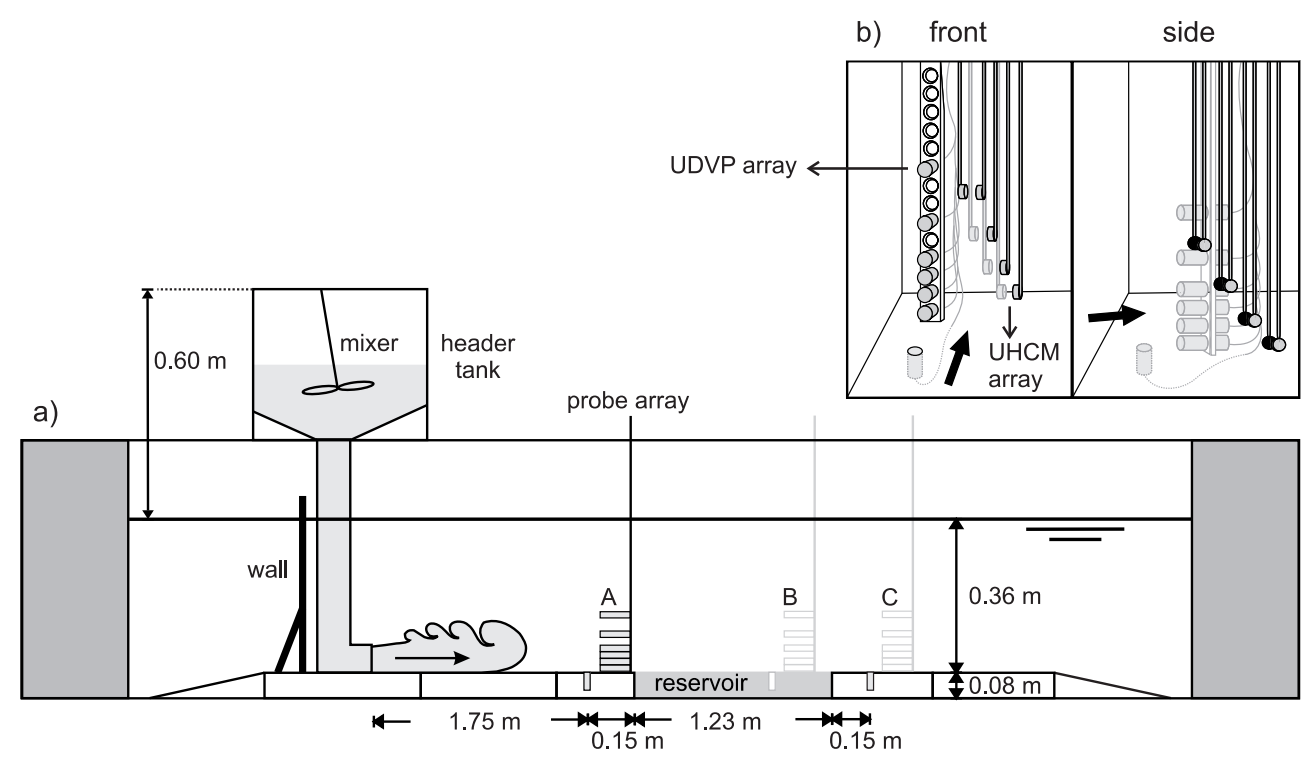

Fig. 1 a) Schematic drawing of the flume set-up (not to scale). The header tank contained a kaolin clay suspension that was released into the flume when the lutocline of the settling mud suspension in the reservoir reached the artificial floor level (the floor has a zero slope). A wall behind the outflow prevented flow in the opposite direction. Each run was repeated three times so that velocities and concentrations could be measured successively at location A, B and C. b) Detailed front and side view of the probe array with the UDVP transducers ( $\varnothing 13$ mm) in a vertical holder in the centre of the channel and the UHCMs $(\varnothing 10 \mathrm{~mm})$ slightly to the right. The bold black arrows indicate the flow direction.

vannah Harbor (McAnally et al, 2007a) and the access channel to Rotterdam Port (Winterwerp and van Kesteren, 2004, page 84); on the continental shelf, like the north-east coast of South America (Wells and Coleman, 1981); and at river mouths, like the Amazon River (Kineke et al, 1996) and Eel River (Traykovski et al, 2000). In the deeper marine environment soft-mud deposits may form through deposition of mud-caps, usually associated with turbidity currents, especially in ponded settings (Amy et al, 2007).

Turbidity currents are known to occur in a wide range of environments, from lakes and reservoirs to fjords and the deep ocean (Middleton, 1993). Thus, it is likely that turbidity currents encounter and deform soft substrates. These fluid mud like substrates are believed to interact differently with a passing turbidity current than a sandy substrate. The cohesive properties of muddy beds make them susceptible to plastic deformation and they may be more or less prone to erosion than sandy beds, depending upon their consolidation state. Plastic deformation or erosion, and subsequent entrainment of cohesive sediment into the flow, might also cause significant changes in the turbulence properties of the turbidity current (Baas and Best, 2002; Baas et al, 2009). Field evidence for bed deformation by turbidity currents in the form of large scale shear structures has been described by Clark and Stanbrook (2001) and Traykovski et al (2000) reported 'wave motions' in the lutocline of a fluid mud bed, potentially caused by Kelvin-Helmholtz instabilities. Felix et al (2009) found wavy interfaces between debris flows and overriding turbulent clouds, with turbidite deposition in the troughs of the waves. However, the interpretation by Felix et al (2009) of the formation of these wavy tops is through shear at the top of the moving debris flow, instead of deformation by the overriding turbidity current.

In this paper, results of flume experiments carried out in the Hydrodynamics Laboratory at Bangor University, Wales (UK) are presented. This descriptive study aims to answer the following research questions: 1) Which types of interaction occur when turbidity currents move over a soft substrate? 2) Can predictions be made about the type of interaction based on the velocity of the current and the concentration contrast between the current and the substrate? 3) Does interaction between the turbidity current and the bed affect the velocity structure of the current?

\section{Methods}

\subsection{Flume set-up}

A total of 84 experiments was carried out in a $10 \mathrm{~m}$ long, $0.3 \mathrm{~m}$ wide and $0.4 \mathrm{~m}$ deep flume (Fig. 1). A header tank (volume: $\sim 50 \mathrm{~L}$ ) with an electrical drill powered mixer was placed on top of the flume (total head: $0.60 \mathrm{~m}$ ) and filled with a clay suspension. By opening a ball valve the suspension drained under gravity from the header tank through an outflow pipe $(\varnothing 23 \mathrm{~cm})$ onto the bottom in the centre of the flume. An initial jet-flow stabilized into a turbidity current over a horizontal, artificial floor section before the flow moved over a prepared soft clay bed. 
A range of volumetric concentrations of medium-sized commercially available kaolin clay (Imerys Polwhite-E) was used for both the turbidity currents and the clay beds (Table 1). The grain size distribution of the kaolin clay was determined using a Malvern Mastersizer 2000 (Fig. 2).

Before each run, siphon samples were taken from the header tank, from the upper $10 \mathrm{~mm}$ of the clay bed, and from 10 and $20 \mathrm{~mm}$ above the clay bed. All sediment samples were weighed and dried to determine their volumetric clay concentration.

An artificial Perspex floor was constructed, $80 \mathrm{~mm}$ above the original flume floor. A missing section in the artificial floor was used as a reservoir for making the clay bed (Fig. 1). This reservoir, with a total volume of $\sim 27 \mathrm{~L}(1230 \mathrm{~mm}$ long, $300 \mathrm{~mm}$ wide and $75 \mathrm{~mm}$ deep), was located $1.9 \mathrm{~m}$ downstream from the outflow opening of the header tank. The clay deposits were created by gravitational settling of well-mixed kaolin clay suspensions with three different initial concentrations. The flume was filled with tap water to $0.36 \mathrm{~m}$ above the artificial floor before the pre-mixed clay suspension was poured in and allowed to settle. This clay mixture was prepared at least one day in advance to allow the clay to become completely saturated with water. Two barriers on either side of the reservoir prevented the suspension from spreading through the flume, thus constricting settling to the reservoir section.

Creating the substrate by settling resulted in vertical concentration gradients within the clay deposit (Fig. 3). Depthaveraged volumetric concentrations, $\mathrm{C}_{\mathrm{b}}$, were 5.6, 7.8 and $8.8 \mathrm{vol} \%$. The average concentrations in the uppermost 10 $\mathrm{mm}$ of the clay deposits, $\overline{\mathrm{C}}_{\mathrm{b}, \mathrm{t}}$, were $2.1,5.7$ and $7.1 \mathrm{vol} \%$ (Table 1), which is equivalent to $55 \mathrm{~kg} \mathrm{~m}^{-3}, 148 \mathrm{~kg} \mathrm{~m}^{-3}$ and $185 \mathrm{~kg} \mathrm{~m}^{-3}$ and thus partly within the fluid mud domain (Fig. 4). A series of control experiments was carried out with a continuous Perspex floor instead of the clay reservoir as the substrate for the turbidity currents.

When the lutocline of the settling suspension in the reservoir reached the same level as the artificial floor, the clay suspension in the header tank was released to produce the bottom-hugging density current. The initial concentrations of the uniformly mixed clay suspensions within the header tank $\left(\overline{\mathrm{C}}_{\mathrm{f}, \mathrm{i}}\right)$ ranged between 0.41 and 15.3 vol\% (Table 1 ). The concentrations of the turbidity currents in the flume were significantly lower due to mixing with the ambient water. At $5 \mathrm{~mm}$ above their base, the currents carried on average between 0.06 and 3.84 vol\% clay in the head $\left(\overline{\mathrm{C}}_{\mathrm{fh}, \mathrm{b}}\right)$ and between 0.10 and 5.43 vol\% clay in the body $\left(\overline{\mathrm{C}}_{\mathrm{fb}, \mathrm{b}}\right)$. These are the average concentrations in the head of control currents, since it was not possible to determine the clay concentration within flows that interacted with the clay bed, due to potential mixing processes. An HD camcorder was used to record the interaction between the turbidity currents and the clay beds, and to track flow geometry within the flume.

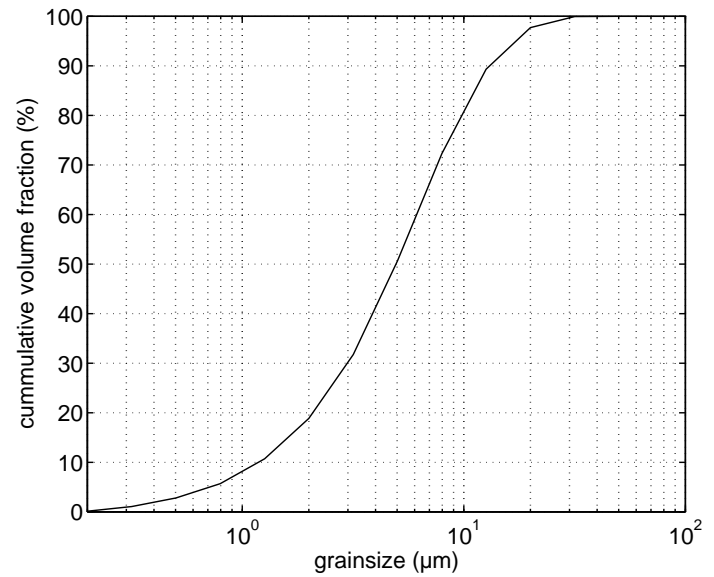

Fig. 2 Cumulative size distribution of Imerys Polwhite-E china clay (kaolin clay), obtained by linear interpolation between 21 measured size classes. D10, D50 and D90 are $1.9 \mu \mathrm{m}, 7.9 \mu \mathrm{m}$ and $20.5 \mu \mathrm{m}$, respectively.

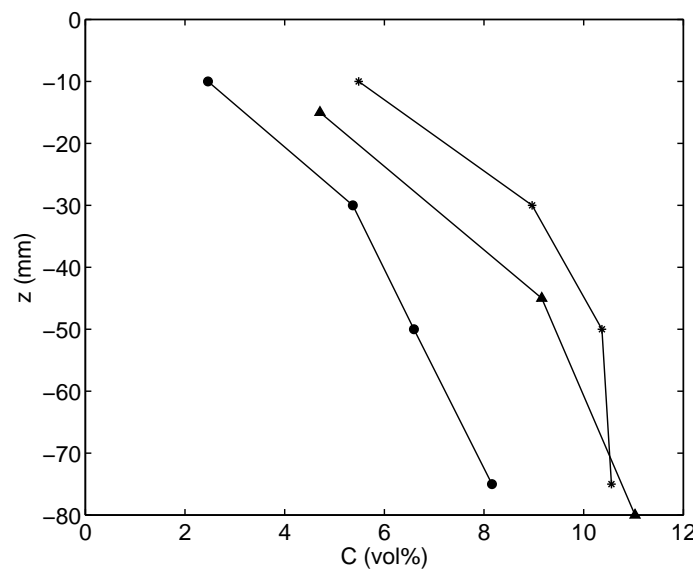

Fig. 3 Concentration profiles in the clay bed shown for the three different initial conditions in this study, with depth averaged concentrations, $\mathrm{C}_{\mathrm{b}}$, of $5.6(\mathrm{o}), 7.8(\triangle)$ and $8.8(*)$ vol\% (Table 1). Data were obtained by means of siphon sampling.

\subsection{UDVP transducers}

Flow velocities were measured with Ultrasonic Doppler Velocity Profiling (UDVP) (Takeda, 1991; Best et al, 2001), using a set-up developed by Met-Flow SA (Switzerland) consisting of a UVP-DUO monitor, specialized software and 2 $\mathrm{MHz}$ acoustic transducers. A UDVP transducer emits an ultrasound pulse and the same transducer receives the echo reflected off particles in the flow. The velocity information is derived using the Doppler shift frequency (Takeda, 1991, 1995). Multiple velocities are measured along a straight line (i.e. measurement window) that is divided into channels. The length of the measurement window and the number of channels govern the spatial resolution of the velocity data (Met-Flow, 2002). At each time-step the transducer mea- 
Table 1 Overview of kaolin clay concentrations used in this study. From left to right: depth-averaged clay concentration for each of the three types of initial bed $\left(\mathrm{C}_{\mathrm{b}}\right)$; average clay concentration within the upper $10 \mathrm{~mm}$ of each type of initial bed $\left(\overline{\mathrm{C}}_{\mathrm{b}, \mathrm{t}}\right)$; average clay concentrations within the header tank $\left(\overline{\mathrm{C}}_{\mathrm{f}, \mathrm{i}}\right)$; time-averaged clay concentrations within the lowest $5 \mathrm{~mm}$ of the head and body of the control currents at location $\mathrm{B}\left(\overline{\mathrm{C}}_{\mathrm{fh}, \mathrm{b}}\right.$ and $\overline{\mathrm{C}}_{\mathrm{fb}, \mathrm{b}}$; Fig. 1).

\begin{tabular}{lllll}
\hline $\begin{array}{l}\mathrm{C}_{\mathrm{b}} \\
(\mathrm{vol} \%)\end{array}$ & $\begin{array}{l}\overline{\mathrm{C}}_{\mathrm{b}, \mathrm{t}} \\
(\mathrm{vol} \%)\end{array}$ & $\begin{array}{l}\overline{\mathrm{C}}_{\mathrm{f}, \mathrm{i}} \\
(\mathrm{vol} \%)\end{array}$ & $\begin{array}{l}\overline{\mathrm{C}}_{\mathrm{fh}, \mathrm{b}} \\
(\mathrm{vol} \%)\end{array}$ & $\begin{array}{l}\overline{\mathrm{C}}_{\mathrm{fb}, \mathrm{b}} \\
(\mathrm{vol} \%)\end{array}$ \\
\hline 5.6 & 2.05 & 0.41 & 0.06 & 0.10 \\
& & 1.05 & 0.16 & 0.21 \\
& & 2.14 & 0.47 & 0.57 \\
& & 5.66 & 1.56 & 2.00 \\
& & 8.49 & 2.36 & 3.10 \\
\hline 7.8 & 5.65 & 0.41 & 0.06 & 0.10 \\
& & 1.05 & 0.16 & 0.21 \\
& & 2.14 & 0.47 & 0.57 \\
& & 5.66 & 1.56 & 2.00 \\
& & 8.49 & 2.36 & 3.10 \\
& & 11.97 & 3.59 & 4.34 \\
& & 15.27 & 3.84 & 5.43 \\
\hline 8.8 & 7.10 & 2.14 & 0.47 & 0.57 \\
& & 5.66 & 1.56 & 2.00 \\
& & 8.49 & 2.36 & 3.10 \\
& & 11.97 & 3.59 & 4.34 \\
& & 15.27 & 3.84 & 5.43 \\
\hline No reservoir & & 0.41 & 0.06 & 0.10 \\
& & 1.05 & 0.16 & 0.21 \\
& & 2.14 & 0.47 & 0.57 \\
& & 5.66 & 1.56 & 2.00 \\
& & 11.49 & 2.36 & 3.10 \\
& & 3.59 & 4.34 \\
& & 3.84 & 5.43 \\
\hline
\end{tabular}

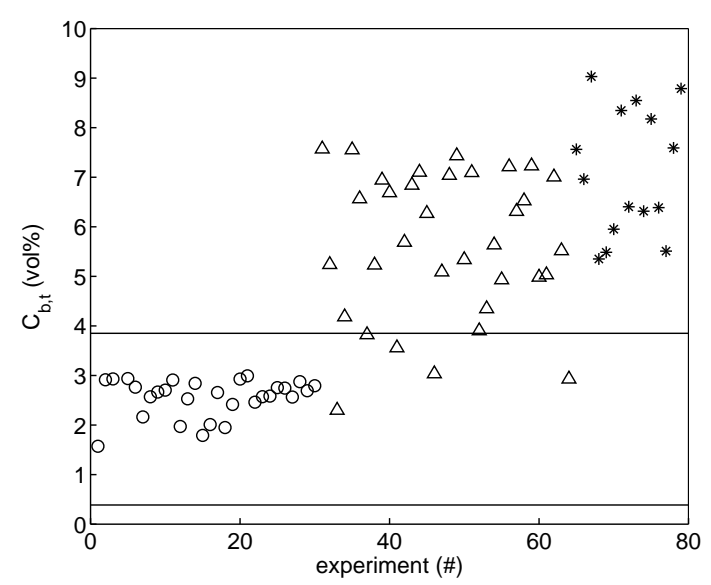

Fig. $4 \mathrm{C}_{\mathrm{b}, \mathrm{t}}$ determined for each experiment from sediment samples taken before each experiment, with averages of $2.1(\mathrm{o}), 5.6(\triangle)$ and $7.1(*) \operatorname{vol} \%\left(\overline{\mathrm{C}}_{\mathrm{b}, \mathrm{t}}\right.$, Table 1$)$. The solid lines represent the upper and lower concentration boundaries of the fluid mud domain.
Table 2 UDVP data acquisition settings.

\begin{tabular}{ll}
\hline Speed of sound in water $\left(\mathrm{ms}^{-1}\right)$ & 1480 \\
Measurement window $(\mathrm{mm})$ & 117.48 \\
Number of channels & 128 \\
Distance between channel centres $(\mathrm{mm})$ & 0.93 \\
Channel width (mm) & 1.48 \\
Frequency of the ultrasound beam $(\mathrm{MHz})$ & 2 \\
Number of cycles* per pulse & 4 \\
Number of sound pulses per measurement & 32 \\
Minimum on-axis velocity $\left(\mathrm{mms}^{-1}\right)$ & -1005.4 \\
Maximum on-axis velocity $\left(\mathrm{mms}^{-1}\right)$ & 997.6 \\
Velocity resolution (mms $\left.{ }^{-1}\right)$ & 7.855 \\
Time between each measurement** (s) & 0.641 \\
\hline *number of wavelengths in the emitted sound pulse \\
**for 8 probes in multiplexer mode, the time between \\
each velocity measurement was $0.08 \mathrm{~s}$
\end{tabular}

sures the flow velocity simultaneously at every channel and the output is a velocity profile over a set distance away from the transducer (Met-Flow, 2002). For the present study, eight UDVP transducers were attached to a probe array and connected in a multiplex setting, resulting in a measurement frequency of $1.56 \mathrm{~Hz}$ for each transducer (see Table 2 for UDVP settings).

Velocity measurements were taken at $1.75 \mathrm{~m}(\mathrm{~A}), 2.98$ $\mathrm{m}$ (B) and $3.28 \mathrm{~m}$ (C) downstream of the outflow point (Fig. 1). Each experiment was repeated three times to allow for measurements at all three locations. Time-series of the horizontal component of flow velocity were acquired using an array of 6 UDVP transducers at locations A and C and an array of 5 UDVP transducers at location B (Fig. 1). The height of the horizontal UDVP transducers was fixed at 8, 22, 36 (A and C only), 50, 78 and $120 \mathrm{~mm}$ above the artificial floor or the clay bed surface.

\subsection{UHCM probes}

In addition to siphon sampling before the experiments, Ultra High Concentration Meters (UHCMs) were used to determine time-series of clay concentration during the experiments. The UHCMs record the attenuation of an ultrasound signal (in volts) between a receiver and a transmitter as a measure of concentration, and they have previously been successfully applied in particulate gravity current studies by Felix et al (2005) and Eggenhuisen and McCaffrey (2011). Four probes were mounted on the frame next to the UDVP probes, with the centres of the probes 5, 20, 45 and $80 \mathrm{~mm}$ above the artificial floor (Fig. 1b).

The probes were calibrated by measuring the sound wave attenuation within kaolin clay suspension samples taken during the experiments, which were subsequently weighed and dried to obtain the clay concentrations. The suspensions were measured in $0.180 \mathrm{~L}$ bottles and continuously mixed with a 
magnetic stirrer to prevent settling of the clay. Each suspension was allowed to homogenize for 1 minute and the attenuation was measured with two UHCMs at a time for $20 \mathrm{~s}$ with a $0.1 \mathrm{~s}$ resolution. The linear best-fit curves and corresponding equations, shown in Fig. 5, were determined using ordinary least squares regression.

\section{Results}

The flume experiments revealed five types of interaction between the turbidity currents and the clay beds (Fig. 6). No interaction between the flow and the bed was observed in relatively dilute flows (Fig. 6a). The clay bed did not have a visible effect on the current shape and the head showed a round, overhanging geometry, similar to turbidity currents moving over a hard substrate (Middleton, 1993).

With increasing clay concentration in the turbidity current and a similar clay concentration in the bed, the flowbed interaction became progressively more severe, evolving from minor deformation (Fig. 6b) to severe mixing and erosion (Fig. 6d).

The waves at the flow-bed interface, caused by soft sediment deformation, were typically 5 to $10 \mathrm{~mm}$ high and 20 to $30 \mathrm{~mm}$ long. The waves travelled along the flow-bed boundary in the direction of the current. Minor erosion was observed at the crests of the waves, where small amounts of clay were ripped up from the bed by the current. Upon entering the clay reservoir section, the front of the turbidity current changed from having a round, overhanging nose to a slightly pointed nose that adhered to the clay bed. The front became progressively more pointed as the current moved down the reservoir section (Fig. 6b).

This change in flow geometry was more pronounced for the 'mixing and erosion' interaction type. In addition to becoming increasingly more pointed, the head of the current was elongating and flattening as it progressed over the clay bed (Fig. 6c). Waves were still visible at the flow-bed interface, but in general, the boundary was less distinct due to strong mixing between the turbidity current and the clay bed, accompanied by erosion to a depth between 5 and 20 $\mathrm{mm}$ into the original clay bed. The mixing and erosion process increased in intensity with increasing flow concentration, and a separate interactive phase of 'severe mixing and erosion' was defined for flows that affected the clay bed $>20 \mathrm{~mm}$ below the bed surface (Fig. 6d). In these cases, the head of the turbidity current was extremely stretched and the waves at the flow-bed boundary were replaced by large, irregular scours and injections, which caused continuous entrainment of clay into the turbidity current.

In the experiment shown in Fig. 6e the $\mathrm{C}_{\mathrm{b}, \mathrm{t}}$ was increased to $6.40 \mathrm{vol} \%$. This resulted in an additional type of interaction, in which no waves formed underneath the flow and there was also no clear sign of erosion or mixing, but the bed was plastically deformed in the form of a bulge (or leading wave) in front of the flow.

This leading wave travelled in front of the turbidity current through the reservoir, along the flow-bed interface. The wave grew as the turbidity current proceeded over the clay bed; it was on average $150 \mathrm{~mm}$ long and typically up to 10 $\mathrm{mm}$ high. A small leading wave was also present in front of turbidity currents in experiments that exhibited waves at the flow-bed interface (Fig. 6b). When mixing and erosion occurred, the leading wave was generally higher $(\sim 20 \mathrm{~mm})$ and the head of the turbidity current was flush against the upstream face of the wave (Fig. 6c). When mixing and erosion processes intensified, the bulge in front of the current no longer had the shape of a wave, but the current still piled up the clay in front of it as it eroded into the substrate (Fig. 6d).

\section{Phase diagram of flow-bed interaction}

The present experimental results imply that the type of bed deformation depends upon the concentration contrast between the current and the bed. The interaction is weak or absent if this contrast is high, whereas strong erosion and mixing take place if the concentration contrast is low. In Fig. 7 the different types of interaction are classified using $\mathrm{C}_{\mathrm{b}, \mathrm{t}}$ (Fig. 4) versus $\overline{\mathrm{C}}_{\mathrm{fh}, \mathrm{b}}$ (Table 1), assuming transverse homogeneity of the turbidity currents.

The flow-bed interaction types occupy distinct regions in the phase diagram (Fig. 7). No interaction takes place, when the near-bed clay concentrations in the turbidity currents are relatively low. In the fluid mud domain this is below 0.50 vol\%, while for higher bed clay concentrations the upper limit of 'no interaction' is above $0.50 \mathrm{vol} \%$. The 'leading wave only' type of interaction occurs at intermediate clay concentrations in the flow and relatively high clay concentrations in the bed, whereas interfacial waves are confined to relatively dilute fluid mud beds. For high near-bed current concentrations in the flow, mixing and erosion is the dominant interaction type. Mixing and erosion in the fluid mud domain is classified as severe, but as the clay concentration in the bed increases, the intensity of the mixing and erosion decreases and is restricted to $<20 \mathrm{~mm}$ below the clay bed surface (Fig. 7).

Within the investigated parameter space, the $\overline{\mathrm{C}}_{\mathrm{fh}, \mathrm{b}}$ appears to have the largest effect on flow-bed interaction, as a relatively small increase $(\sim 1 \mathrm{vol} \%)$ in current clay concentration is sufficient to change from a stable bed ("no interaction') via wave development to severe mixing and erosion. Increases in $\mathrm{C}_{\mathrm{b}, \mathrm{t}}$ show an opposite trend toward progressively weaker flow-bed interaction. However, none of the experiments were conducted at a sufficiently wide range 


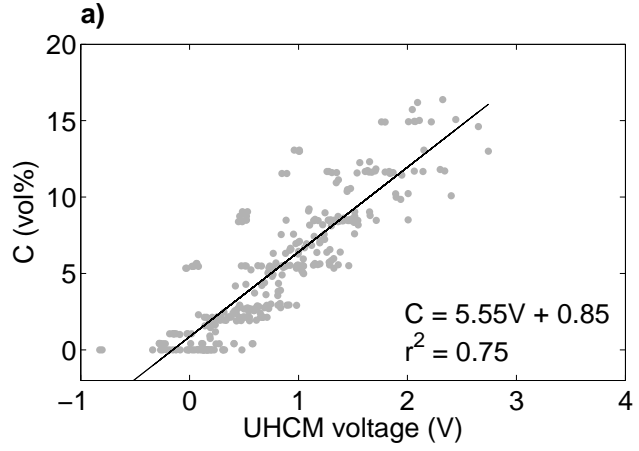

c)

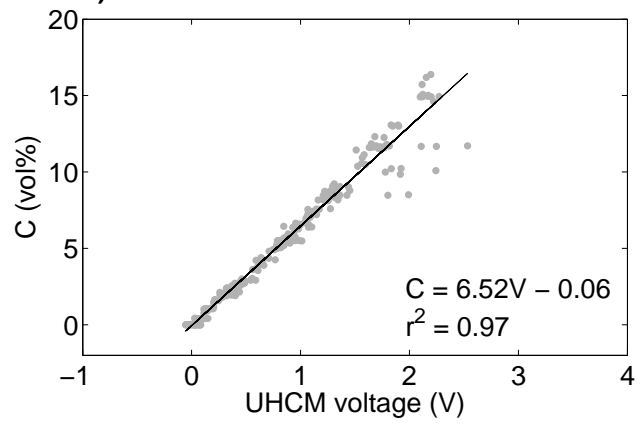

b)

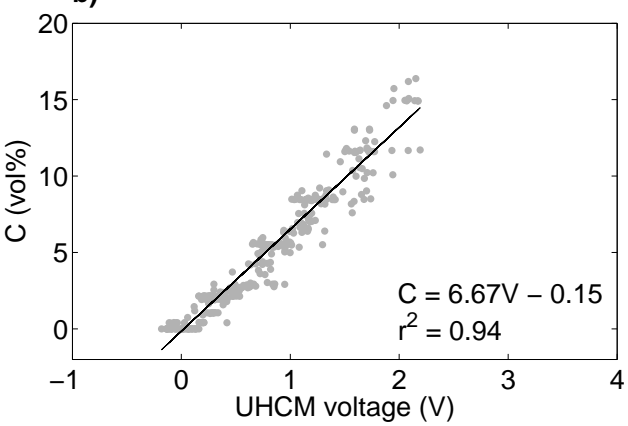

d)

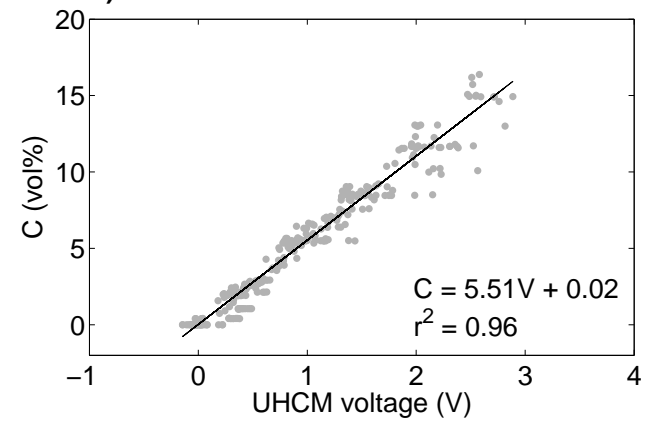

Fig. 5 Calibration curves of each UHCM for kaolin clay (probe 1-4 in a-d respectively). Corresponding equations and correlation coefficients are shown as well. Curves were obtained by measuring and subsequently weighing and drying sediment samples.

of current clay concentrations to cover the entire range of interaction types for a single bed clay concentration.

The phase diagram in Fig. 7 is based on flow and bed concentrations which are merely a proxy for the forces that control the interaction between the moving turbidity current and the underlying clay bed. A shear stress exists at the flowbed interface due to an off-balance between the flow forcing and the resisting forces in the bed. The forces applied by the flow were approximated by the overall momentum calculated for the flows' head and body. The mechanical resistance in the bed comprises the density contrast between the flow and the bed and the resistant shear stresses in the top of the bed. The amount of deformation at the interface should scale with these forces.

Figure 8 shows a non-dimensional classification of the different interaction types described by parameters related to the acting force balance. Ri is defined as a density-related Richardson number in the head (Eq. 1) and body (Eq. 2) of the flow using the temporal mean velocity and density:

$\mathrm{Ri}_{\mathrm{h}}=\frac{\left(\rho_{\mathrm{b}, \mathrm{t}}-\rho_{\mathrm{fh}, \mathrm{b}}\right) g d}{\rho_{\mathrm{fh}, \mathrm{b}} U_{\mathrm{h}, \mathrm{b}}^{2}}$

$\mathrm{Ri}_{\mathrm{b}}=\frac{\left(\rho_{\mathrm{b}, \mathrm{t}}-\rho_{\mathrm{fb}, \mathrm{b}}\right) g d}{\rho_{\mathrm{fb}, \mathrm{b}} U_{\mathrm{b}, \mathrm{b}}^{2}}$ where $\rho_{\mathrm{b}, \mathrm{t}}$ is the density in the top $10 \mathrm{~mm}$ of the bed, $\rho_{\mathrm{fh}, \mathrm{b}}$ and $\rho_{\mathrm{fb}, \mathrm{b}}$ are the average densities in the head and body of the control current with the same initial concentration as the interaction experiment, $g$ is the gravitational acceleration $\left(=9.81 \mathrm{~m} \mathrm{~s}^{-2}\right), d$ is the thickness of the mobilized part of the kaolin clay bed, approximated here by the total thickness (= $80 \mathrm{~mm}$ ), and $U_{\mathrm{h}, \mathrm{b}}$ and $U_{\mathrm{b}, \mathrm{b}}$ are the time-averaged velocities in the head and body of the flow.

The bulk densities of the bed and the head and body of the turbidity current were calculated using the volumetric concentrations and the relative densities of kaolin clay $\left(\rho_{\mathrm{k}}=\right.$ $\left.2600 \mathrm{~kg} \mathrm{~m}^{-3}\right)$ and the ambient water $\left(\rho_{\mathrm{a}}=1000 \mathrm{~kg} \mathrm{~m}^{-3}\right)$ :

$\rho_{\mathrm{b}, \mathrm{t}}=\left(\rho_{\mathrm{k}}-\rho_{\mathrm{a}}\right) * \frac{\mathrm{C}_{\mathrm{b}, \mathrm{t}}}{100}+\rho_{\mathrm{a}}$

$\rho_{\mathrm{fh}, \mathrm{b}}=\left(\rho_{\mathrm{k}}-\rho_{\mathrm{a}}\right) * \frac{\overline{\mathrm{C}}_{\mathrm{fh}, \mathrm{b}}}{100}+\rho_{\mathrm{a}}$

$\rho_{\mathrm{fb}, \mathrm{b}}=\left(\rho_{\mathrm{k}}-\rho_{\mathrm{a}}\right) * \frac{\overline{\mathrm{C}}_{\mathrm{fb}, \mathrm{b}}}{100}+\rho_{\mathrm{a}}$

The shear strength of clay rich suspensions is usually quantified by the shear modulus or the yield stress, however no rheological measurements were done on the kaolin 


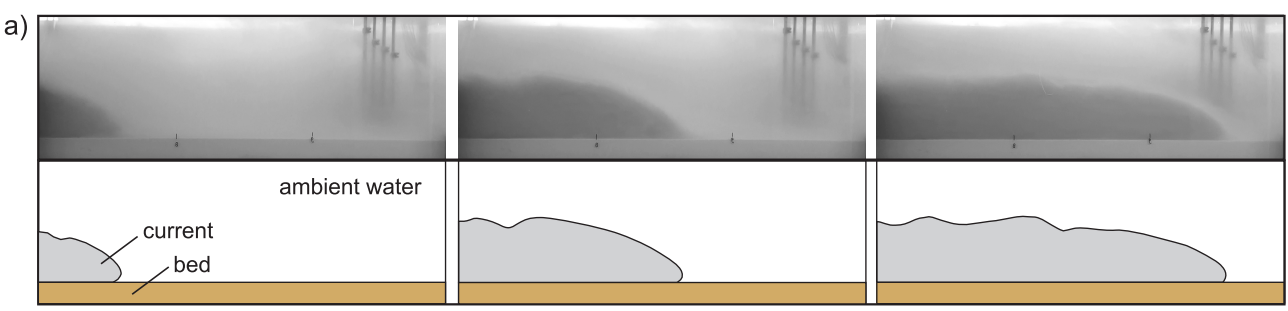

b)
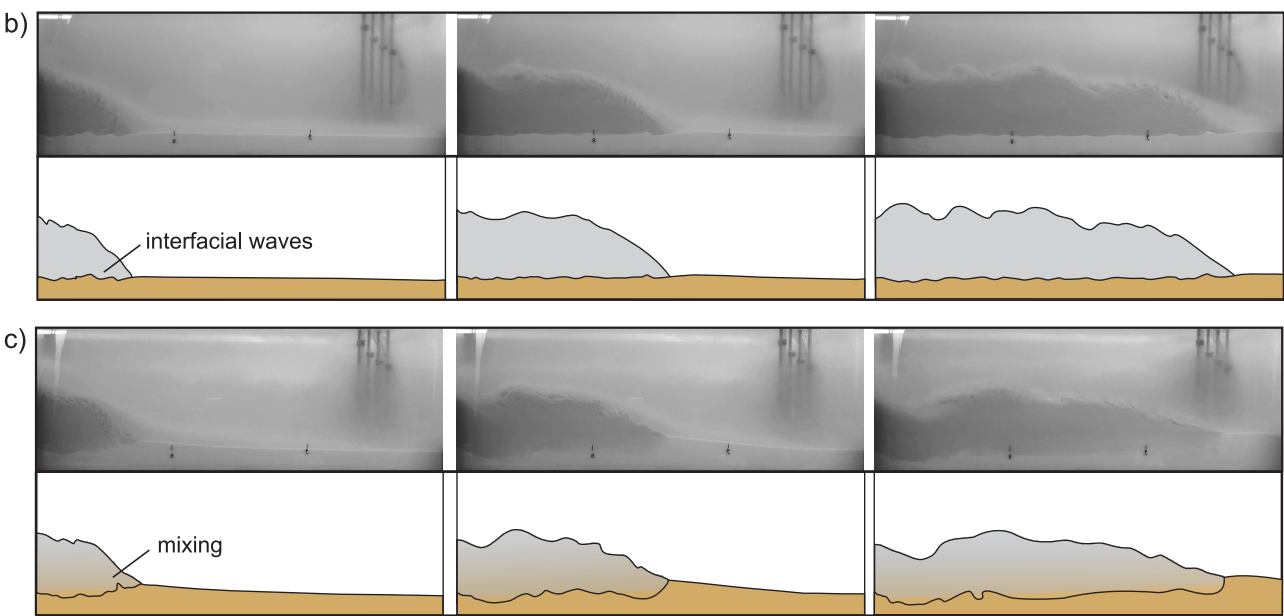

d)
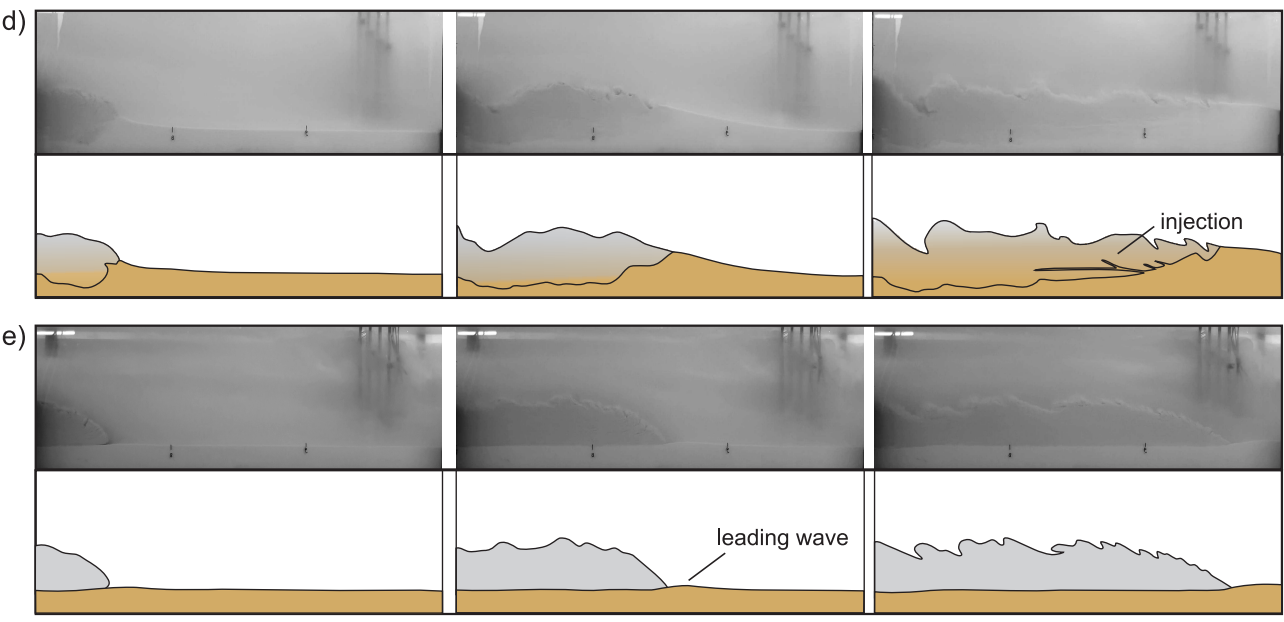

$30 \mathrm{~cm}$

Fig. 6 Video stills and corresponding drawings of five experiments, showing the following types of flow-bed interaction: a) no interaction; b) interfacial waves; c) mixing and erosion; d) severe mixing and erosion; e) leading wave only. Successive points in time are shown from left to right. Brown colour denotes clay in the bed, grey colour denotes clay in the turbidity current. $\mathrm{C}_{\mathrm{b}, \mathrm{t}}$ was similar for a-d with a) 2.93 , b) 2.67 , c) 2.42 and d) 2.87 , but increased in e) to 6.40 vol $\%$; $\mathrm{C}_{\mathrm{f}, \mathrm{i}}$ increased from a to d, with a) $0.41 \mathrm{vol} \%$, b) 2.15 vol $\%$, c) $5.50 \mathrm{vol} \%$ and d-e) 8.49 vol $\%$.

clay used in this study. Strength related parameters present a strong dependence (power-law) on the sediment concentration (e.g. Wan (1982), for kaolinite). Instead of a strength parameter, the bed density was used to separate the regions in the diagram where the bed had no strength, i.e. below a presumed gel concentration of $100 \mathrm{~kg} \mathrm{~m}^{-3}$, and where yield stresses may be developed. The relative bed density was calculated using:

where $\rho_{\text {gel }}$ is the gel density $\left(=1061 \mathrm{~kg} \mathrm{~m}^{-3}\right)$ for a gel concentration of $100 \mathrm{~kg} \mathrm{~m}^{-3}$.

As in the concentration-based phase diagram, the different flow-bed interaction types fill separate areas in the non-dimensional diagram in both the head and the body of the flow (Fig. 8). Again, the momentum applied by the flow 
1

2

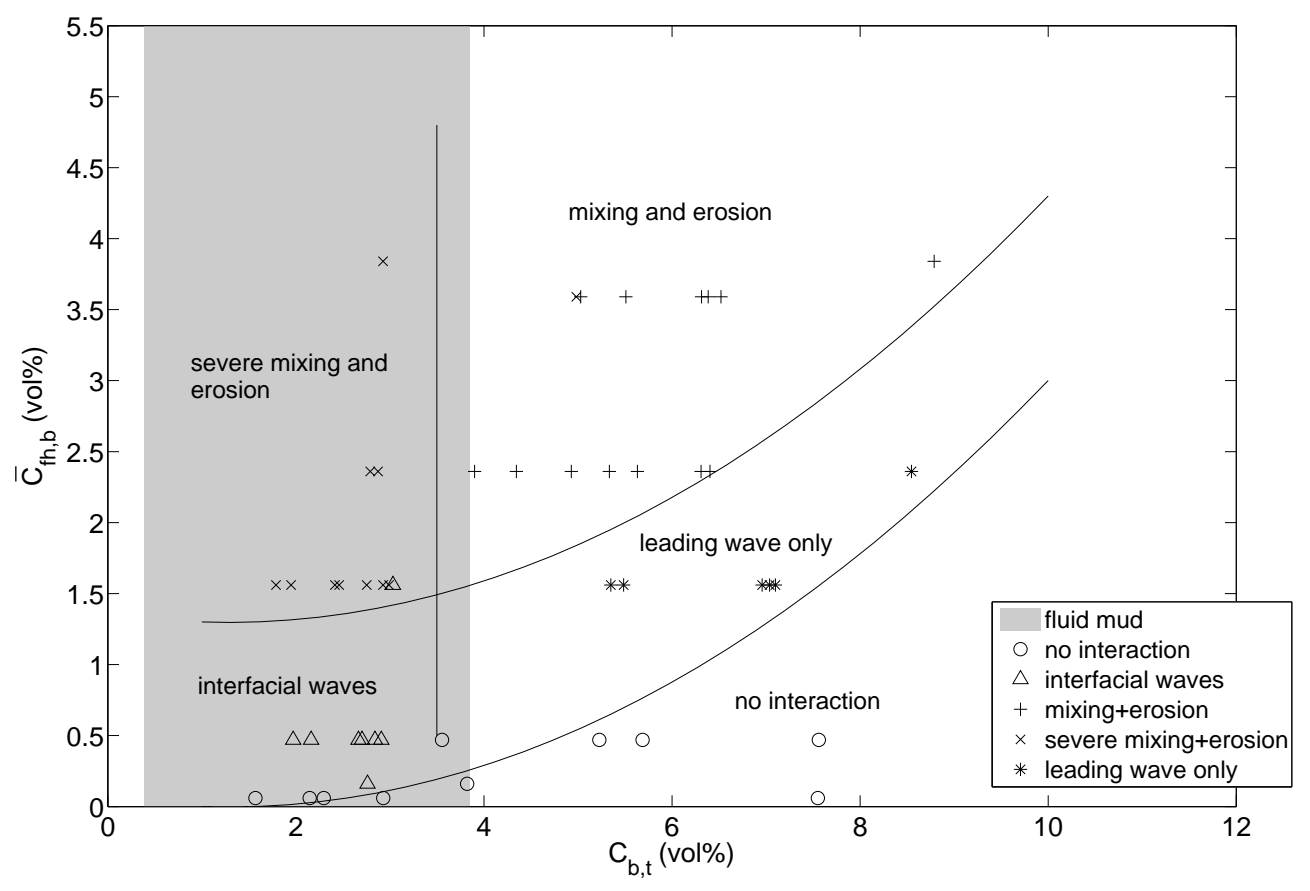

Fig. 7 Phase diagram for different types of interaction between clay-laden turbidity currents and soft, muddy substrates based on volumetric concentrations in the head of the control current, $\overline{\mathrm{C}}_{\mathrm{fh}, \mathrm{b}}$, and upper $10 \mathrm{~mm}$ of the clay bed, $\mathrm{C}_{\mathrm{b}, \mathrm{t}}$. The grey area represents the fluid mud domain. The lines separate the different types of flow-bed interaction: 'no interaction', 'interfacial waves', 'leading wave only', 'mixing and erosion' and 'severe mixing and erosion'.

a)

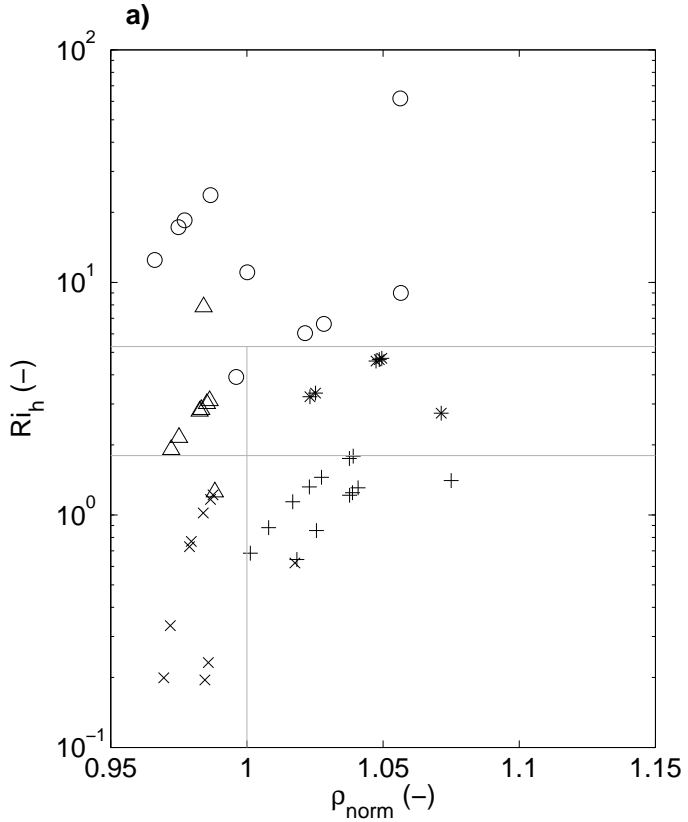

b)

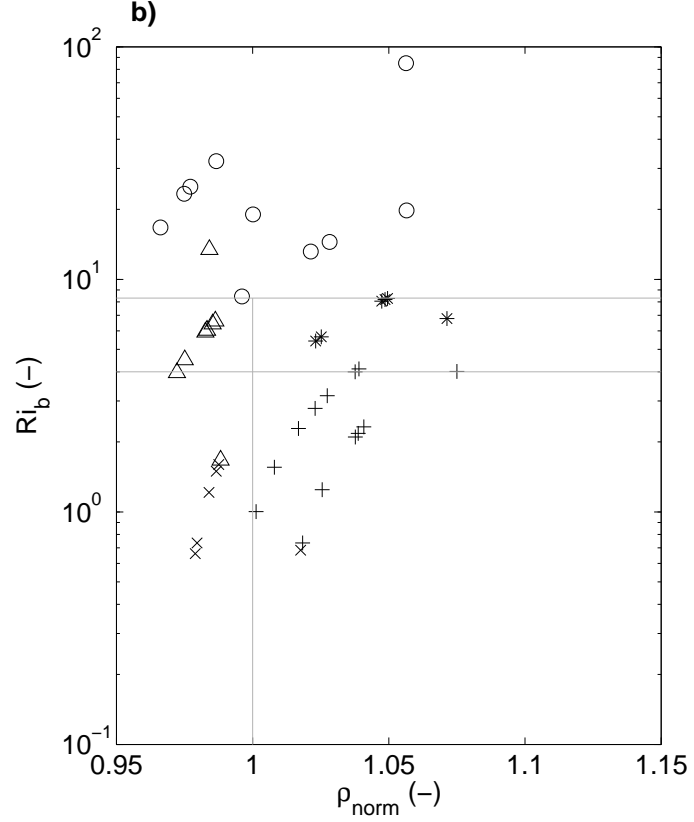

Fig. 8 Non-dimensional phase diagram for flow-bed interaction between the head (a) and body (b) of clay-laden turbidity currents and soft, kaolin substrates. The parameters $\mathrm{Ri}_{\mathrm{h}}, \mathrm{Ri}_{\mathrm{b}}$ and $\rho_{\text {norm }}$ on the $\mathrm{x}$ and y axis are defined in Eqs 1, 2 and 6 . The different interaction types are represented by symbols as in Fig. 7: (o) no interaction, $(\triangle)$ interfacial waves, (+) mixing and erosion, (x) severe mixing and erosion and (*) leading wave only. The grey lines indicate the separations between the different flow-bed interactions as discussed in the text. 
$\left(\mathrm{Ri}_{\mathrm{h}}\right.$ and $\left.\mathrm{Ri}_{\mathrm{b}}\right)$ has a stronger effect on the flow-bed interaction than the resistant forces within the bed $\left(\rho_{\text {norm }}\right)$. For a constant bed density, but an increase in Ri caused by a decrease in the mean velocity or flow density, the deformation at the flow-bed interface decreases strongly.

The non-dimensional diagrams consist of a region where the density is below the gel concentration and the beds have no strength $\left(\rho_{\text {norm }}<1\right)$ and a region for where the density is above the gel concentration and the beds have a yield strength $\left(\rho_{\text {norm }}>1\right)$.

In the region for which $\rho_{\text {norm }}<1$, the deformation increases with decreasing $\mathrm{Ri}$ and three zones can be identified: 1) no interaction for $\mathrm{Ri}_{\mathrm{h}}>5$ and $\mathrm{Ri}_{\mathrm{b}}>8.3$; 2) waves at the flow-bed interface, stabilized by the density contrast, for $1.8<\mathrm{Ri}_{\mathrm{h}}<5$ and $4<\mathrm{Ri}_{\mathrm{b}}<8.3$; and 3 ) severe mixing and erosion at $\mathrm{Ri}_{\mathrm{h}}<1.8$ and $\mathrm{Ri}_{\mathrm{b}}<4$.

In the region above the gel concentration similar zones can be distinguished but the deformation at the flow-bed interface is less pronounced: 1) no interaction for $\mathrm{Ri}_{\mathrm{h}}>5$ and $\mathrm{Ri}_{\mathrm{b}}>8.3 ; 2$ ) a leading wave in front of the current due to plastic deformation but no deformation underneath the current for $1.8<\mathrm{Ri}_{\mathrm{h}}<5$ and $4<\mathrm{Ri}_{\mathrm{b}}<8.3$; and 3) mixing and erosion restricted to the top $20 \mathrm{~mm}$ of the bed for $\mathrm{Ri}_{\mathrm{h}}<1.8$ and $\mathrm{Ri}_{\mathrm{b}}<4$.

\section{Discussion}

Before the bed can be affected dynamically and thus flowbed interaction occurs, the forcing stresses by the current need to exceed the resisting stresses in the bed. In the present experiments an increase in $\mathrm{C}_{\mathrm{f}, \mathrm{i}}$ increased the outflow velocity of the turbidity current in the flume because of an increased density difference with the ambient water. A higher initial concentration therefore contributed to a higher average velocity of the flow across the clay reservoir (Middleton, 1966). The relationship between $C_{\text {fh,b }}$ and maximum flow velocity in the head, $U_{\mathrm{h}, \max }$, is plotted in Fig. 9 and approximates $\mathrm{C}_{\mathrm{fh}, \mathrm{b}} \sim U_{\mathrm{h} \text {,max }}^{2.74}$. Equations 1 and 2 show that an increase in $\mathrm{C}_{\mathrm{fh}, \mathrm{b}}$ results in a decrease in $\mathrm{Ri}$ and thus an increase in the observed flow-bed interaction (Fig. 8).

The phase diagrams in Figs 7 and 8 show that there is a transitional region between 'no interaction' and 'mixing and erosion', where waves form at the flow-bed interface and the bed is deformed plastically. This sets cohesive, muddy substrates apart from loose, sandy substrates, for which erosion occurs immediately when the critical bed shear stress for particle movement is exceeded.

Soft muddy beds with a density below $1061 \mathrm{~kg} \mathrm{~m}^{-3}$ exhibit interaction with the flow in the form of interfacial waves, while for beds with a higher density, waves are absent underneath the current and a single leading wave is formed in front of the nose of the turbidity current (Fig. 7).

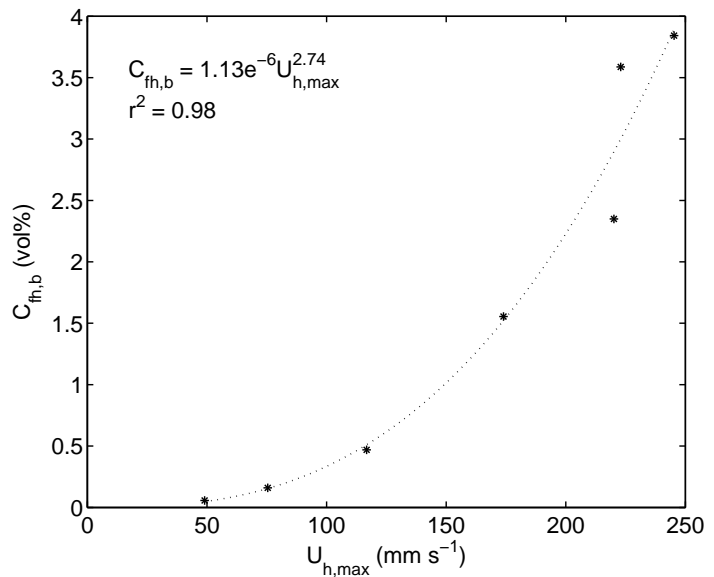

Fig. 9 Maximum in the time-averaged horizontal velocity profiles $\left(U_{\mathrm{h}, \max }\right)$ of 7 turbidity currents in control experiments plotted against the average clay concentration in the lowest $5 \mathrm{~mm}$ of the head of the same currents $\left(\mathrm{C}_{\mathrm{fh}, \mathrm{b}}\right)$. The best fit curve is shown as a dotted line.

In the normalised phase diagram (Fig. 8) the same transition is present.

This difference in flow-bed interaction may be explained by spatial changes in the force balance. In the interfacial wave' phase field, the bed has no strength and the turbulent stresses of the current are strong enough to induce oscillations at the flow-bed interface, despite the fact that the flow gradually decelerates in time (Fig. 10). In the 'leading wave only' phase field, however, the bed has a yield stress and only the relatively high mean and instantaneous forces at the arrival of the turbidity current are able to deform the bed at the higher resisting forces, but the turbulent stresses of the current are too low to develop waves at the flow-bed interface. The gradual decrease in velocity with time also explains the shift in phase boundaries for the head and body of the flow (Fig. 8), since Ri increases with a decrease in the velocity at a constant flow concentration (Eq. 1 and 2).

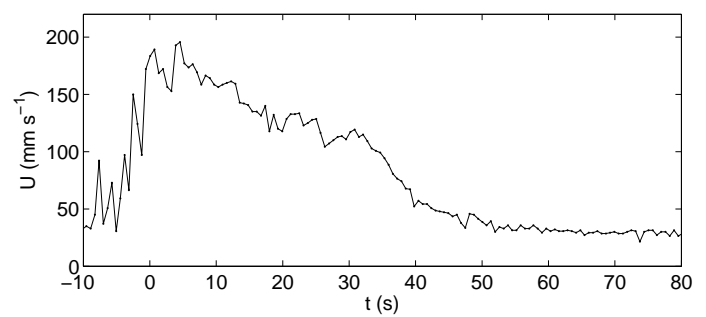

Fig. 10 Velocity time-series showing the gradual decrease in velocity after arrival of the turbidity current at the UDVP transducers $(\mathrm{t}=0$ s) at a fixed height of $50 \mathrm{~mm}$ above the bed, for a current with $\mathrm{C}_{\mathrm{f}, \mathrm{i}}=$ $5.49 \mathrm{vol} \%, \mathrm{C}_{\mathrm{b}, \mathrm{t}}=5.35 \mathrm{vol} \%$ and a 'leading wave only' interaction type. This temporal deceleration is present in all turbidity currents discussed in this study. 
Experimental turbidity currents have a characteristic vertical profile of horizontal velocity, which is the result of drag along the base and the top of the turbidity current (Altinakar et al, 1996; Kneller et al, 1999). Interaction of the turbidity current with the bed increases the drag at the lower boundary. It is therefore expected that the velocity profile of the turbidity current is modified, and that this modification is greater if the interaction between the flow and the bed is more severe. This hypothesis is confirmed by the velocity data in Fig. 11, which compares the time-averaged head velocities of turbidity currents $\left(U_{h}\right)$ flowing over the kaolin clay bed with control experiments where the flow advances over the artificial floor. These velocity data were collected at location B (Fig. 1) and the dimensions of the head of each turbidity current were determined from the video, velocity and concentration data, following McCaffrey et al (2003).

Figure 11a shows the velocity profiles for a flow which had no visible interaction with the clay bed. The decrease in velocity near the bed may be due to the clay bed surface being somewhat rougher than the artificial floor. The velocity does not differ significantly from the control run higher in the flow.

With the initial interaction between the flow and the bed (Fig. 11b), considerable changes in the velocity profile become apparent. Again, the flow velocity in the lower part of the turbidity current is lower, caused in this case not only by the roughness of the clay bed, but also by the energy loss due to deformation of the flow-bed interface. Furthermore, the height of maximum velocity has shifted upwards. This near-bed decrease in velocity and upward shift of the velocity maximum is also observed for the 'leading wave only' interaction type (Fig. 11c).

In case of mixing and erosion at the flow-bed boundary (Fig. 11d), the velocity profile of the turbidity current shows a distinct velocity decrease which is inferred to be caused by energy loss due to strong interaction between the flow and the bed. The flattening of the head, as observed in the video data (Fig. 6), is also shown in the velocity profile.

If the clay bed is subjected to severe mixing and erosion (Fig. 11e), the flow thickness is reduced strongly and its velocity reduced in most parts of the flow. However, the nearbed flow deceleration, which is characteristic of all other interaction types (Fig. 11a-d) and expected to be severe for this interaction type, does not exceed $25 \%$ of the near-bed velocity in the control experiment. This may be at least partly due to the fact that the UDVP transducers measured higher in the turbidity current relative to the eroding bed surface.

Changes in flow velocity caused by flow-bed interaction could have a significant impact on the run-out distance of a turbidity current that encounters a soft clay bed. If the current is actively slowed down by processes of mixing and erosion (Fig. 11), as opposed to the common notion that bed erosion will accelerate the turbidity current as a result of a
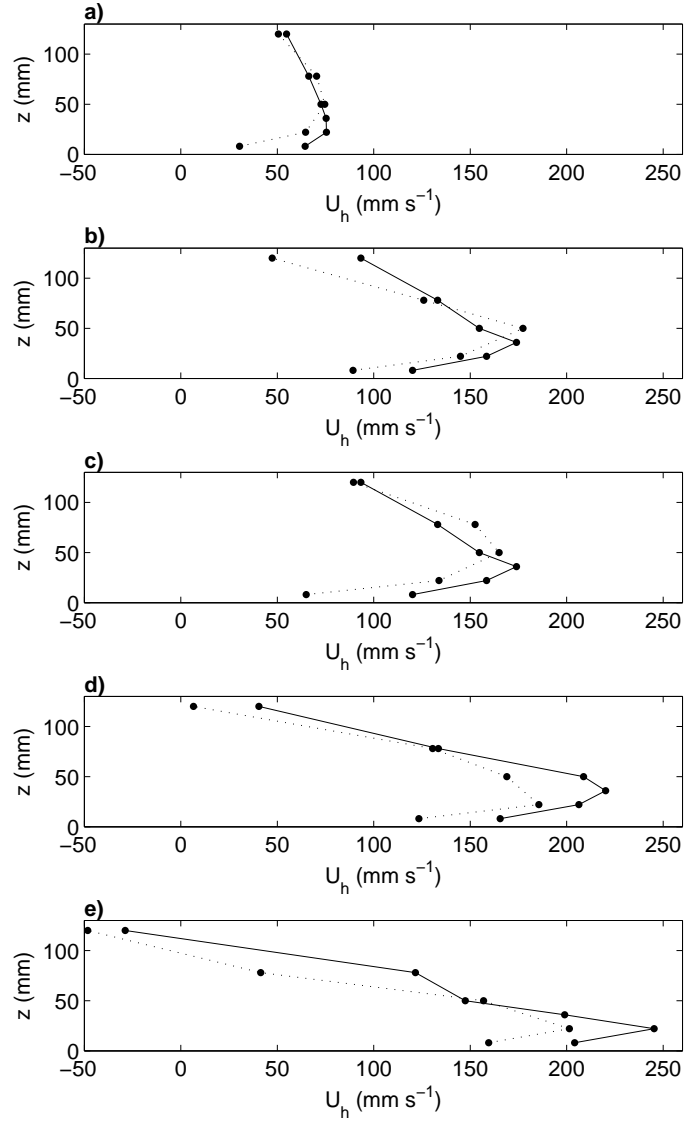

Fig. 11 Velocity profiles of time-averaged head velocity $\left(U_{h}\right)$ against height above the bed $(z)$ for turbidity currents flowing over the clay bed (dotted line) and the artificial floor (solid line) for each type of flowbed interaction: a) no interaction; b) interfacial waves; c) leading wave only; d) mixing and erosion; e) severe mixing and erosion. $\mathrm{C}_{\mathrm{b}, \mathrm{t}}$ is a) 3.82 ; b) 3.03 ; c) 5.35 ; d) 3.90 ; and e) $2.93 \mathrm{vol} \%$. $\overline{\mathrm{C}}_{\text {fh, }}$ is a) 0.16 ; b) 1.56 ; c) 1.56 ; d) 2.36 ; and e) $3.84 \mathrm{vol} \%$.

greater density difference with the ambient water, the sediment carrying capacity of the current will decrease (Hiscott, 1994) and it is therefore forced to deposit part of its sediment load. This will reduce the density contrast between the flow and the ambient water, and hence decrease the flow velocity even further. This positive feedback mechanism could potentially lead to a rather rapid collapse of the turbidity current.

This paper has classified the main types of interaction between clay-laden turbidity currents and soft, muddy beds. As such, the results provide a qualitative tool that may help to explain the flow behaviour of fine-grained turbidity currents and depositional products of such flows in basins where clay-rich beds and fluid muds are known to occur, such as muddy estuaries, continental margins and deep oceans. In 
addition, the results of this study increase understanding of fluid mud behaviour and might contribute to fluid mud management, for instance in harbours and channels, and increase understanding of nutrient and contaminant dynamics in the natural environment (McAnally et al, 2007a,b).

\section{Conclusions}

Five types of flow-bed interaction are identified for kaolinclay laden turbidity currents that flow over soft kaolin-clay beds: 1) no interaction; 2) interfacial waves; 3 ) leading wave only; 4) mixing and erosion; and 5) severe mixing and erosion. Two phase diagrams are presented: 1) a concentrationbased phase diagram that plots the clay concentrations within the upper $10 \mathrm{~mm}$ of the bed against the average near-bed clay concentration measured in the head of the control currents; 2) a non-dimensional phase diagram that uses a densityrelated Richardson number and the density of the mud bed to approximate the force balance between the flow and the bed. Both diagrams separate the different types of flow-bed interaction well within the studied parameter space. Interactions between turbidity currents and the soft, muddy beds are able to modify the near-bed flow velocities, which might have important implications for the general flow behaviour and run-out distance of natural turbidity currents.

Acknowledgements This work was carried out as part of a PhD studentship, funded through the Turbidites Research Group by Anadarko, BG Group, BHP-Billiton, BP, ConocoPhillips, Maersk Oil, Marathon Oil, Nexen, Statoil, Tullow Oil plc and Woodside. We would like to thank Johanna Illers who collected part of the UHCM data and Gareth Keevil from the University of Leeds for supplying the header tank and UHCMs. Han Winterwerp and an anonymous reviewer are thanked for their constructive comments that helped improve the manuscript.

\section{Nomenclature}

$$
\begin{array}{ll}
\mathrm{C} & \begin{array}{l}
\text { kaolin clay concentration (vol\%) } \\
\mathrm{C}_{\mathrm{b}}
\end{array} \\
\mathrm{C}_{\mathrm{b}, \mathrm{t}} & \begin{array}{l}
\text { depth-averaged kaolin clay concentration in the } \\
\text { bed (vol\%) } \\
\text { kaolin clay concentration in the upper } 10 \mathrm{~mm} \text { of } \\
\text { the bed (vol\%) }
\end{array} \\
\overline{\mathrm{C}}_{\mathrm{b}, \mathrm{t}} & \begin{array}{l}
\text { average kaolin clay concentration in the upper } \\
10 \mathrm{~mm} \text { of the bed for each bed type (vol\%) }
\end{array} \\
\mathrm{C}_{\mathrm{f}, \mathrm{i}} & \begin{array}{l}
\text { initial kaolin clay concentration in the flow } \\
\text { (header tank suspension) (vol\%) }
\end{array} \\
\overline{\mathrm{C}}_{\mathrm{f}, \mathrm{i}} & \begin{array}{l}
\text { average initial kaolin clay concentration (vol\%) } \\
\text { time-averaged concentration in the lower } 5 \mathrm{~mm} \\
\mathrm{C}_{\mathrm{fb}, \mathrm{b}}
\end{array} \\
& \begin{array}{l}
\text { of the body of currents moving over the mud bed } \\
\text { (vol\%) }
\end{array}
\end{array}
$$
$\overline{\mathrm{C}}_{\mathrm{fb}, \mathrm{b}} \quad$ time-averaged kaolin clay concentration in the lower $5 \mathrm{~mm}$ of the body in control cur- rents (vol\%)
$\mathrm{C}_{\mathrm{fh}, \mathrm{b}} \quad$ time-averaged kaolin clay concentration in the lower $5 \mathrm{~mm}$ of the head of currents mov- ing over the mud bed (vol\%)
$\overline{\mathrm{C}}_{\mathrm{fh}, \mathrm{b}}$ time-averaged kaolin clay concentration in the lower $5 \mathrm{~mm}$ of the head in control cur- rents (vol\%)
$d \quad$ thickness of mobilized kaolin clay bed $(=80$ $\mathrm{mm}$ )
$g \quad$ gravitational acceleration $\left(=9.81 \mathrm{~m} \mathrm{~s}^{2}\right)$
$\mathrm{Ri}_{\mathrm{h}}$ density-related Richardson number in the head of the current (Eq. 1) (-)
$\mathrm{Ri}_{\mathrm{b}}$ density-related Richardson number in the body of the current (Eq. 2) (-)
$U_{\mathrm{h}} \quad$ time-averaged head velocity $\left(\mathrm{mm} \mathrm{s}^{-1}\right)$
$U_{\mathrm{h}, \mathrm{b}} \quad$ time-averaged near-bed velocity in the head or body of the current (lower $5 \mathrm{~mm})(\mathrm{mm}$ $\mathrm{s}^{-1}$ )
$U_{\mathrm{b}, \mathrm{b}} \quad$ time-averaged near-bed velocity in the head or body of the current (lower $5 \mathrm{~mm})(\mathrm{mm}$ $\mathrm{s}^{-1}$ )
$U_{\mathrm{h}, \max }$ maximum head velocity $\left(\mathrm{mm} \mathrm{s}^{-1}\right)$
$z \quad$ height above the bed ( $\mathrm{mm}$ )
$\rho_{\mathrm{a}} \quad$ relative density of the ambient water $(=1000$ $\mathrm{kg} \mathrm{m}^{-3}$ )
$\rho_{\mathrm{b}, \mathrm{t}} \quad$ density in the upper $10 \mathrm{~mm}$ of the bed $(\mathrm{kg}$ $\mathrm{m}^{-3}$ )
$\rho_{\mathrm{fh}, \mathrm{b}} \quad$ time-averaged density in lower $5 \mathrm{~mm}$ of the head of the control currents $\left(\mathrm{kg} \mathrm{m}^{-3}\right)$
$\rho_{\mathrm{fb}, \mathrm{b}} \quad$ time-averaged density in lower $5 \mathrm{~mm}$ of the body of the control currents $\left(\mathrm{kg} \mathrm{m}^{-3}\right)$
$\rho_{\text {gel }} \quad$ gel concentration $\left(=1061 \mathrm{~kg} \mathrm{~m}^{-3}\right)$
$\rho_{\mathrm{k}} \quad$ relative density of kaolin clay $(=2600 \mathrm{~kg}$ $\mathrm{m}^{-3}$ )
$\rho_{\text {norm }} \quad$ normalised bed density (-)

\section{References}

Altinakar MS, Graf WH, Hopfinger EJ (1996) Flow structure in turbidity currents. J Hydraul Res 34(5):713-718

Amy LA, Kneller BC, McCaffrey WD (2007) Facies architecture of the Grès de Peira Cava, SE France: landward stacking patterns in ponded turbiditic basins. J Geol Soc 164:143-162

Baas JH, Best JL (2002) Turbulence modulation in clay-rich sediment-laden flows and some implications for sediment deposition. J Sediment Res 72(3):336-340

Baas JH, Best JL (2008) The dynamics of turbulent, transitional and laminar clay-laden flow over a fixed current ripple. Sedimentology 55:635-666 
Baas JH, Best JL, Peakall J, Wang M (2009) A phase diagram for turbulent, transitional, and laminar clay suspension flows. J Sediment Res 79:162-183

Baas JH, Best JL, Peakall J (2011) Depositional processes, bedform development and hybrid bed formation in rapidly decelerated cohesive (mud-sand) sediment flows. Sedimentology 58:1953-1987

Baas JH, Davies AG, Malarkey J (2013) Bedform development in mixed sand-mud: The contrasting role of cohesive forces in flow and bed. Geomorphology 182:19-32

Best JL, Kirkbridge AD, Peakall J (2001) Mean flow and turbulence structure of sediment-laden gravitiy currents: new insights using ultrasonic Doppler velocity profiling. In: McCaffrey WD, Kneller BC, Peakall J (eds) Particulate Gravity Currents, International Association of Sedimentologists, Special Publication, 31, Blackwell Science Ltd., pp 159-172

Butler RWH, Tavarnelli E (2006) The structure and kinematics of substrate entrainment into high-concentration sandy turbidites: a field example from the Gorgoglione 'flysch' of southern Italy. Sedimentology 53:655-670

Chowdhury MR, Testik FY (2011) Laboratory testing of mathematical models for high-concentration fluid mud turbidity currents. Ocean Eng 38:256-270

Clark JD, Stanbrook DA (2001) Formation of large-scale shear structures during deposition from high-density turbidity currents, Grès d'Annot Formation, south-east France. In: McCaffrey WD, Kneller BC, Peakall J (eds) Particulate Gravity Currents, International Association of Sedimentologists, Special Publication, 31, Blackwell Science Ltd., pp 219-232

Coussot P (1997) Mudflow Rheology and Dynamics. IAHRAIRH Monograph Series, A. A. Balkema, Rotterdam

Dickhudt PJ, Friedrichs CT, Sanford LP (2011) Mud matrix solids fraction and bed erodibility in the York River estuary, USA, and other muddy environments. Cont Shelf Res 31:S3-S13

Eggenhuisen JT, McCaffrey WD (2011) The vertical turbulence structure of experimental turbidity currents encountering basal obstructions: implications for vertical suspended sediment distribution in non-equilibrium currents. Sedimentology 59(3):1101-1120

Eggenhuisen JT, McCaffrey WD, Haughton PDW, Butler RWH (2010) Small-scale spatial variability in turbiditycurrent flow controlled by roughness resulting from substrate erosion: field evidence for a feedback mechanism. J Sediment Res 80:129-136

Felix M, Peakall J (2006) Transformation of debris flows into turbidity currents: mechanisms inferred from laboratory experiments. Sedimentology 53:107-123

Felix M, Sturton S, Peakall J (2005) Combined measurements of velocity and concentration in experimental turbidity currents. Sediment Geol 179(1-2):31-47
Felix M, Leszczynski S, Slaczka A, Uchman A, Amy L, Peakall J (2009) Field expressions of the transformation of debris flows into turbidity currents, with examples from the Polish Carpathians and the French Maritime Alps. Mar Pet Geol 26(10):2011-2020

Hiscott RN (1994) Loss of capacity, not competence, as the fundamental process governing deposition from turbidity currents. J Sediment Res A64(2):209-214

Houwing EJ, van Rijn LC (1998) In Situ Erosion Flume (ISEF): determination of bed-shear stress and erosion of a kaolinite bed. J Sea Res 39:243-253

Houwing EJ, Van Rijn LC (1994) In-situ determination of the critical bed-shear stress for erosion of cohesive sediments. In: Edge BL (ed) Coastal Engineering, Proceedings of the Twenty-Fourth International Conference, Japan Society of Civil Engineers, Kobe, Japan, pp 20582069

Hsu SK, Kuo J, Lo CL, Tsai CH, Doo WB, Ku CY, Sibuet JC (2008) Turbidity currents, submarine landslides and the 2006 Pingtung earthquake off SW Taiwan. Terr Atmos Ocean Sci 19(6):767-772

Jacobs W, Le Hir P, van Kesteren W, Cann P (2011) Erosion threshold of sand-mud mixtures. Cont Shelf Res 31:S14S25

Khripounoff A, Vangriesheim A, Babonneau N, Crassous P, Dennielou B, Savoye B (2003) Direct observation of intense turbidity current activity in the Zaire submarine valley at $4000 \mathrm{~m}$ water depth. Mar Geol 194(3-4):151158

Kineke GC, Sternberg RW, Trowbridge JH, Geyer WR (1996) Fluid-mud processes on the Amazon continental shelf. Cont Shelf Res 16:667-696

Kneller BC, Buckee C (2000) The structure and fluid mechanics of turbidity currents: a review of some recent studies and their geological implications. Sedimentology 47:62-94

Kneller BC, Bennett SJ, McCaffrey WD (1999) Velocity structure, turbulence and fluid stresses in experimental gravity currents. J of Geophys Res 104(3):5381-5391

Kothyari UC, Jain RK (2010) Erosion characteristics of cohesive sediment mixtures. In: Dittrich A, Aberle J, Geisenhainer P (eds) River Flow 2010, Bundesanstalt für Wasserbau, pp 815-821

Marr JG, Harff PA, Shanmugam G, Parker G (2001) Experiments on subaquous sandy gravity flows: The role of clay and water content in flow dynamics and depositional structures. Geol Soc Am Bull 113(11):1377-1385

McAnally WH, Friedrichs C, Hamilton D, Hayter E, Shrestha P, Rodriguez H, Sheremet A, Teeter A (2007a) Management of fluid mud in estuaries, bays, and lakes. I: Present state of understanding on character and behavior. J Hydraul Eng 133(1):9-22 
McAnally WH, Teeter A, Schoellhamer D, Friedrichs C, Hamilton D, Hayter E, Shrestha P, Rodriguez H, Sheremet A, Kirby R (2007b) Management of fluid mud in estuaries, bays, and lakes. II: Measurement, modeling, and management. J Hydraul Eng 133(1):23-38

McCaffrey WD, Choux CMA, Baas JH, Haughton PDW (2003) Spatio-temporal evolution of velocity structure, concentration and grain-size stratification within experimental particulate gravity currents. Mar Pet Geol 20:851860

Mehta A (1991) Understanding fluid mud in a dynamic environment. Geo-Mar Lett 11:113-118

Met-Flow (2002) UVP Monitor, Model UVP-DUO with Software Version 3, User's Guide, 5th edn. Met-Flow SA, Avenue Mon-Repos 14, CH1005 Lausanne, Switzerland

Middleton GV (1966) Small-scale models of turbidity currents and the critereon for auto-suspension. J Sediment Petrol 36(1):202-208

Middleton GV (1993) Sediment deposition from turbidity currents. Annu Rev Earth Planet Sci 21:89-114

Nichols MM (1984) Fluid mud accumulation processes in an estuary. Geo-Mar Lett 4(3-4):171-176

Odd NVM, Cooper AJ (1989) A two-dimensional model of the movement of fluid mud in a high energy turbid estuary. J Coast Res (SI5):185-193

Takeda Y (1991) Development of an ultrasound velocity profile monitor. Nucl Eng Des 126:277-284

Takeda Y (1995) Instantaneous velocity profile measurement by ultrasonic Doppler method. Jpn Soc Mech Eng Int J 38:8-16

Traykovski P, Geyer WR, Irish JD, Lynch JF (2000) The role of wave-induced density-driven fluid mud flows for cross-shelf transport on the Eel River continental shelf. Cont Shelf Res 20:2113-2140

Wan Z (1982) Bed material movement in hyperconcentrated flow. Series Paper 31, Institute of Hydrodynamics and Hydraulic Engineering, Technical University of Denmark, Lyngby

Wells JT, Coleman JM (1981) Physical processes and finegrained sediment dynamics, coast of Surinam, South America. J Sediment Pet 51:1053-1068

Whitehouse R, Soulsby R, Roberts W, Mitchener H (2000) Dynamics of estuarine muds. Thomas Telford Publishing, London

Winterwerp JC, van Kesteren WGM (2004) Introduction to the physics of cohesive sediment in the marine environment. Elsevier, Amsterdam

Xu JP, Noble MA, Rosenfeld LK (2004) In-situ measurements of velocity structure within turbidity currents. Geophys Res Lett 31(L09311), DOI 10.1029/2004GL019718 


\section{Review: list of comments and changes 2}

\section{Comments - Han Winterwerp}

Note: $1-39 / 42 \mathrm{R}$ refers to page 1 , lines $39-42$, right column.

1. In abstract you refer to 'substrate with fluid mud properties'. Elsewhere in the ms you are much more subtle, and distinguishes between fluid mud and soft deformable mud (1-39/R). Please be consistent, and make proper reference in the abstract.

- The term 'fluid mud domain' was used more carefully.

- 1-26/27L '...over a substrate with fluid-mud properties.' changed to '...over a soft mud substrate.'

- 1-42/43R Section added before start of the second paragraph:

'Soft, muddy sediments with concentrations between several to hundreds of $\mathrm{kg} \mathrm{m}^{-3}$ are referred to as fluid mud deposits (e.g. Nichols, 1984; Odd and Cooper, 1989; Kineke et al, 1996; Whitehouse et al, 2000; Winterwerp and van Kesteren, 2004; McAnally et al, 2007). Winterwerp and van Kesteren (2004) defined fluid mud as a cohesive sediment suspension with a concentration at or beyond the gelling point, in the order of several 10 to $100 \mathrm{~kg} \mathrm{~m}^{-3}$. This concentration range is used in the present study as the interval in which a fluid mud can develop ('fluid mud domain').

- 2-49/50R '...over a prepared clay bed with fluid-mud like properties.' replaced with '...over a prepared soft clay bed.'

- 3-25/39 Rephrased section:

Original section 'The average concentrations in the uppermost $10 \mathrm{~mm}$ of the clay deposits, $\overline{\mathrm{C}}_{\mathrm{b}, \mathrm{t}}$, were $2.1,5.7$ and 7.1 vol\% (Table 1 ), which is equivalent to $55 \mathrm{kgm}^{-3}, 148 \mathrm{kgm}^{-3}$ and $185 \mathrm{kgm}^{-3}$. The deposits therefore fall into the fluid mud domain, which is typically between $20-200 \mathrm{kgm}^{-3}$, although this value is dependent on cohesiveness of the sediment and the depositional environment (Whitehouse et al, 2000). Typical fluid mud concentrations found in estuaries are in the order of several 10 to $100 \mathrm{kgm}^{-3}$ (Winterwerp, 2002; Winterwerp and van Kesteren, 2004), which is the concentration range of the "fluid mud regime' used in this study (Fig. 4). Below the gel concentration, presumed close to $100 \mathrm{kgm}^{-3}$ in this study, no structure between the clay particles has developed and therefore the deposit has no strength.' 
Rephrased section 'The average concentrations in the uppermost $10 \mathrm{~mm}$ of the clay deposits, $\overline{\mathrm{C}}_{\mathrm{b}, \mathrm{t}}$, were 2.1, 5.7 and $7.1 \mathrm{vol} \%$ (Table 1), which is equivalent to $55 \mathrm{~kg} \mathrm{~m}^{-3}, 148 \mathrm{~kg} \mathrm{~m}^{-3}$ and $185 \mathrm{~kg} \mathrm{~m}^{-3}$ and thus partly within the fluid mud domain (Fig. 4).

- 5-51/52R 'Mixing and erosion for fluid-mud beds is classified...' changed to 'Mixing and erosion in the fluid mud domain is classified...'

- 7-46/50L Rephrased:

Original section 'Instead of a strength parameter, the bed density was used to separate the regions in the diagram where the bed had no strength (fluid mud regime) and where yield stresses may be developed.'

Rephrased section 'Instead of a strength parameter, the bed density was used to separate the regions in the diagram where the bed had no strength, i.e. below a presumed gel concentration of $100 \mathrm{~kg} \mathrm{~m}^{-3}$, and where yield stresses may be developed.'

- 7-50/52R 'fluid mud' removed from sentence.

- 7-56R 'In the fluid mud region...' replaced by 'In the region for which $\rho_{\text {norm }}<1$...'

- 9-1/3R 'Fluid-mud beds (sensu Winterwerp and van Kesteren 2004) exhibit interaction...' rephrased: 'Soft muddy beds with a density below $1061 \mathrm{~kg}$ $\mathrm{m}^{-3}$ exhibit interaction...'.

- 9-3/4R '...while at bed clay concentrations above the gel concentration, waves...' rephrased: '... while for beds with a higher density, waves...'

- 10-55/56R '...flow over fluid-mud like, kaolin-clay beds....' rephrased '...flow over soft kaolin-clay beds:...'

2. 5/15L and Fig 6, and elsewhere in text: You have distinguished five regimes, but Fig. 6 contains only four, whereas the text suggests Fig. 6 depicts five. Please correct.

- Figure 6 was updated to contain all five interaction regimes. The figure caption was updated:

Original caption 'Video stills and corresponding drawings of four experiments, showing the following types of flow-bed interaction: a) no interaction; b) interfacial waves; c) (severe) mixing and erosion; d) leading wave only. Successive points in time are shown from left to right. Brown colour denotes clay in the bed, grey colour denotes clay in the turbidity current. $\mathrm{C}_{\mathrm{b}, \mathrm{t}}$ was similar for a-c with a) 2.93 , b) 2.67 and c) 2.42 , but increased in d) to $6.40 \mathrm{vol} \%$; $\mathrm{C}_{\mathrm{f}, \mathrm{i}}$ increased from a to d, with a) 0.41 vol\%, b) 2.15 vol $\%$, c) 5.50 vol $\%$ and d) 8.49 vol\%.'

Rephrased caption 'Video stills and corresponding drawings of five experiments, showing the following types of flow-bed interaction: a) no interaction; b) interfacial waves; c) mixing and erosion; d) severe mixing and erosion; e) leading wave only. Successive points in time are 
shown from left to right. Brown colour denotes clay in the bed, grey colour denotes clay in the turbidity current. $\mathrm{C}_{\mathrm{b}, \mathrm{t}}$ was similar for a-d with a) 2.93 , b) 2.67 , c) 2.42 and d) 2.87 , but increased in e) to 6.40 vol\%; $\mathrm{C}_{\mathrm{f}, \mathrm{i}}$ increased from a to d, with a) $0.41 \mathrm{vol} \%$, b) $2.15 \mathrm{vol} \%$, c) 5.50 vol\% and d-e) 8.49 vol\%.'

- References to Fig. 6 were adjusted in the text:

5-26R '...evolving from minor deformation (Fig. 6b) to mixing and erosion (Fig. 6c).' to '...evolving from minor deformation (Fig. 6b) to severe mixing and erosion (Fig. 6d).'

5-57R '...mm below the bed surface.' to 'mm below the bed surface (Fig. $6 d)$.'

5-3/4L 'In the experiment shown in Fig. $6 \mathrm{~d}$ the $\mathrm{C}_{\mathrm{b}, \mathrm{t}}$ was increased to 6.40 vol\% and the $\mathrm{C}_{\mathrm{f}, \mathrm{i}}$ to 8.49 vol\%.' to 'In the experiment shown in Fig. $6 \mathrm{e}$ the $\mathrm{C}_{\mathrm{b}, \mathrm{t}}$ was increased to $6.40 \mathrm{vol} \%$.'

5-17L '...exhibited waves at the flow-bed interface.' to '...exhibited waves at the flow-bed interface (Fig. 6b).'

5-19/20L '...upstream face of the wave.' to '...upstream face of the wave (Fig. 6c)'

5-23/24L '...eroded into the substrate (Fig. 6c).' to '...eroded into the substrate (Fig. 6d).'

3. 5-30L: I would omit reference to Kelvin-Helmholtz instabilities - these are special instabilities inducing turbulence.

- The term Kelvin-Helmholtz was removed and page 5 lines 28-34 were rephrased:

Original section 'The waves at the flow-bed interface were typically 5 to $10 \mathrm{~mm}$ high and 20 to $30 \mathrm{~mm}$ long. These wave-like structures are likely to be Kelvin-Helmholtz instabilities, since the bed density in the upper $10 \mathrm{~mm}$ of the bed is presumed to be below the gel concentration and thus no plastic deformation or shear waves are able to develop.'

Rephrased section 'The waves at the flow-bed interface, caused by soft sediment deformation, were typically 5 to $10 \mathrm{~mm}$ high and 20 to 30 mm long.'

4. 6-40/R: check dimensions of $\mathrm{g}$.

- Units of $g$ corrected from $\mathbf{m} \mathbf{s}^{2}$ to $\mathbf{m} \mathbf{s}^{-2}$. 


\section{Additional changes to the original manuscript}

- 1-35/39R Two references added after '...erodibility of cohesive beds': Baas et al $(2011,2013)$

- 1-57R '..mud deposits form through deposition' changed to '...mud deposits may form through deposition'

- $2-55 \mathrm{~L}$ 'In this paper, preliminary results...' changed to 'In this paper, results...'

- Page 4, Table 2 clarified time between measurements: time between measurements $=0.641 \mathrm{~s}$ in multiplexer mode for 8 probes, whereas the time between each velocity measurement is $0.08 \mathrm{~s}$.

- 4-59R '...within kaolin clay suspensions samples...' changed to '...within kaolin clay suspension samples...'

- Caption of Fig. 4 (4-53/54L): 'The solid lines represent the upper and lower concentration boundaries of fluid-mud as defined by Winterwerp and van Kesteren (2004)' changed to 'The solid lines represent the upper and lower concentration boundaries of tge fluid mud domain.'

- 5-22/23R '...current still 'piled up' the clay...' changed to '...current still piled up the clay...'

- Equations in Fig. 5 were corrected: the plus signs in the equations in Fig. 5 b and $\mathrm{c}$ were replaced by a minus sign.

- Caption Fig. $5(+)$ removed, since symbols are now dots.

- 6-40/41R '...mobilized part of kaolin clay bed...' changed to '...mobilized part of the kaolin clay bed...'

- 6-45R 'The bulk densities of the bed and in the head and body...' changed to 'The bulk densities of the bed and the head and body...'

- Caption Fig. 7: 'The grey area represents the fluid-mud boundaries as defined by Winterwerp and van Kesteren (2004).' changed to 'The grey area represents the fluid mud domain.'

- 9-41/42L '...an increase $\mathrm{C}_{\mathrm{f}, \mathrm{i}}$ increased...' changed to '...an increase in $\mathrm{C}_{\mathrm{f}, \mathrm{i}}$ increased...'

- $10-15 \mathrm{R}$ '...which is characteristic in all other interaction types...' changed to '...which is characteristic of all other interaction types...'

- $12-56 / 57 \mathrm{R}$ '...profile measurment by...' changed to '...profile measurement by...'

- Resolved inconsistent use of fluid-mud versus fluid mud: removed the hyphens.

- Resolved inconsistent use of spacing for units (in particular $\mathrm{kg} \mathrm{m}^{-3}$ ). 


\section{References}

Baas JH, Best JL, Peakall J (2011) Depositional processes, bedform development and hybrid bed formation in rapidly decelerated cohesive (mud-sand) sediment flows. Sedimentology 58:1953-1987

Baas JH, Davies AG, Malarkey J (2013) Bedform development in mixed sand-mud: The contrasting role of cohesive forces in flow and bed. Geomorphology 182:19-32

Kineke GC, Sternberg RW, Trowbridge JH, Geyer WR (1996) Fluid-mud processes on the Amazon continental shelf. Cont Shelf Res 16:667-696

McAnally WH, Friedrichs C, Hamilton D, Hayter E, Shrestha P, Rodriguez H, Sheremet A, Teeter A (2007) Management of fluid mud in estuaries, bays, and lakes. I: Present state of understanding on character and behavior. J Hydraul Eng 133(1):922

Nichols MM (1984) Fluid mud accumulation processes in an estuary. Geo-Mar Lett 4(3-4):171-176

Odd NVM, Cooper AJ (1989) A two-dimensional model of the movement of fluid mud in a high energy turbid estuary. J Coast Res (SI5):185-193

Whitehouse R, Soulsby R, Roberts W, Mitchener H (2000) Dynamics of estuarine muds. Thomas Telford Publishing, London

Winterwerp JC (2002) On the flocculation and settling velocity of estuarine mud. Cont Shelf Res 22(9):1339-1360

Winterwerp JC, van Kesteren WGM (2004) Introduction to the physics of cohesive sediment in the marine environment. Elsevier, Amsterdam 